UJBM, Vol. 2, No. 2, July - December 2003, pp 67-73

ISSN 0975-3311

https:/ / doi.org/ 10.12725/ ujbm.3.7

\title{
CHANGE MANAGEMENT
}

\section{J. Subramanian*}

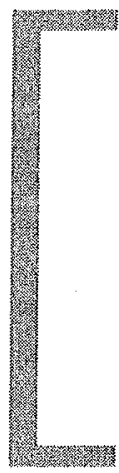

Change is dynamic and positive in nature. Change pre-supposes stability and growth. Identifying and implementing right changes at the right time is the challenging task of modern management. Any change emulates resistance due to inherent inertia and fear. Change agents' job is to eliminate the fear and instill confidence to successfully implant the change. Change management is the art of blending the diverse responses with the discrete organizational goals in an ever-changing business environment. Change management is never a one shot replacement but a sequenced stage by stage progress towards elimination of resistance in favor of the change objective.

Change is the buzzword in the present day life. Life is changing with time and time is changing fast with the advancement in science and technology. The change is more significantly perceptible in a competitive environment where survival and sustenance is the key. Proven methods and practices of the past may no longer be effective or reliable due to change of the variables like consumer preferences, consumer behavior and attitude, general awareness levels, fashion, innovations, time concerns etc. The generally highlighted issues of generation gap, schools of thought, cultural differences and the like are, all-arising from change. Life styles and participations change. Natural delegation of tasks among members of a family - mother responsible for the household and father, the breadwinner and the appellate authority - is no more natural. With the women folk getting into career path, the family management is changing towards a concept of equality and convenience.

* Management Consultant. E-mail: subramaniani@hotmail.com 
Change, mostly occurs by default and develops itself into a system. Such system, if it is able to withstand the test of time towards effective achievement of it's objective, shall remain in force until a new scenario necessitating a change, surfaces. Our school time story of the cap seller who was clever enough to repossess the caps taken by the monkeys, while he was resting under the banyan tree takes a new version with change of time. Now the monkeys are cleverer, having learned the foolery of their forefathers. So they do not throw away the caps they had taken, imitating the cap seller, instead, take away even the last cap of the cap seller and say thank you with a giggle! - A case of previously tested method failingl

Change is often misunderstood as conflict. A conflict may follow a change but change by itself is not conflict. Whatever activity, system, procedure or method that is different from what is at the present may be referred to as a Change. In a business environment change may be with reference to policy matters, technical issues, organizational hierarchy, administrative protocols, functional authorities and procedures, reporting forms and details, personnel matters, amalgamations and mergers and so on. A change from the present is conceived to be for good for the user but until that is tested it is less convincing for the user to accept it. The reason for a change may be internal or external to the organization. A change necessitated by a statutory prescription or due to change in controlling interests - as in the case of sale, amalgamation or merger - could be termed as external factors, while a change resulting from restructuring of the organization, expansion or contraction of the business operations and the like could be termed as internal factors. Change arising from external factors pose lesser problem for acceptance as compared to change arising from internal factors.

Change in its true sense is a dynamic concept and is neither arbitrary nor whimsical. It is related to time, which is moving. Change has to happen to meet the demands of the changing needs to maintain the organizational position. Often it is a solution to the problem of challenges. Change therefore, is a positive trait that a growing organization, has to cultivate. Change instills managerial effectiveness. An organization that shuns change seldom grows. Change process has to be a decision based on logical analysis of its cause and effect. Where change does not happen by default, it has to be engineered in pursuance of the organizational goals.

Management hierarchy may change due to business diversification or activity expansion-a larger operation will call for introduction of new levels of management structure for effective control. Remuneration practices may change to enhance performance efficiency - incremental remuneration linked to production, sales or profitability etc. Marketing strategies may change to meet the challenges from competition or to be at par with the competition - the advent of electronic business 
has put many products on the Internet. Objectives and ideologies may change to match new responsibilities - an educational institution getting a University status would have to re-frame its objectives and plans. Education plan may change to suit the career opportunities in demand - with specializations in the field of career development, the students of education are more inclined to choose career prospective courses than going for the traditional programs of engineering or medicine. Thus change has become a necessity for survival and success. It is more of a management tool to deal with business challenges.

Change has to be managed. If change is a necessity and if it can occur by default, why should it be managed? Can it not happen as a normal routine? In principle the change transformation has to be smooth and without any hurdles. However in reality it is never a smooth operation. Change faces umpteen stumbling blocks in the process of its implementation. The basic human nature is egocentric. Every individual, therefore, has a natural tendency to reject an alternate thought, unless it is self-initiated. A change proposal loses its perspective in the conflict of the mental blocks. Inability to synchronize personal goals to organizational objectives is the fundamental obstacle to change implementation. This aspect has to be highlighted, clarified and convinced to the user group in order to effectively implement the change. Change has to be managed, preferably within the organization by a select change management team, which will create confidence in the user group. Only when it is improbable to identify a competent change management team from within, the service of a change agent is relied on. The hardest disadvantage in using an external change agent arises from the fact that if the agent is not able to objectively appreciate the change management goals the implementation plan will lose its focus and could even torpedo the change process forever. It is imperative that the change agent is conversant and competent to handle the change.

Generally quoted theory on change process is suggested by Kurt Lewin in 'Frontiers in Group Dynamics'. 'Unfreezing - Changing - Refreezing' are the three steps postulated for effecting change. Breaking down the 'existing' is referred to as unfreezing while 'formalizing the change' is stated as refreezing. This is easier perceived than put to effect. In realistic practice change process is neither a separable feature as indicated nor can it be restricted to an equated compliance. A going concern has to continue its activity without hindrance and hence a 'transition phase' has to necessarily follow the 'changing' before the change may refreeze. The process of 'changing' is the most difficult aspect of change process and quite often it takes place only in stages. Change sequencing must match with relevant resistance elimination. More appropriate representation of change process shall be 'Defreeze - Change transition - Refreeze' which establishes the logical sequence. While change process is being put on trial the 'existing' has to co-exist. For example, 
manual processing of data continues while the computerization is on trial, as otherwise there may not be a fall back option in case of failure of computerization.

Change management covers the entire gamut of conceptualization, conviction and congruence of the change. The three Cs of change management are significant as they lay the foundation of change management. The change management process mainly constitutes the following elements:

- Change idea: Change idea originates the need for a change. Any change idea is substantiated by sound reasoning as to why the change is contemplated. Unless the reasoning is strong enough to support the change, it may not be proceeded with. A sound and logical change idea assists in conceptualizing the change. A conceptualized change idea is needed to determine the specifics of the change. It identifies and analyses the change proposal distinctively and objectively. This is a top management function.

- Change objective: Change idea must always carry an objective that may be quantified. The objective has to be for ultimate value enhancement for the user organization, as otherwise the change process may not produce congruence. The change objective must create the conviction to initiate the change process. Conviction must be evidenced by a change model evaluation. The change model must consider all affecting variables and forces that will impact the change. Change model evaluation separates the controllable and non-controllable factors and has to study the probability of non-controllable dominance. The change objective dominated by a high degree of noncontrollable factors cannot ensure the conviction that is needed to proceed with the change implementation. This is also a top management function with inputs from analytical experts.

- Change consequence: Factors affected by the change and the effect of the change on the factors summarizes the change consequence. Organisational factors affected by change could be either financial resources or human resources or both. Management of change with reference to human resources tends to be the most critical in the change consequence. A change proposal duly conceptualized and tested for conviction has to adequately address the change consequence to acquire congruence. Change process is never complete without congruence of the affected factors. This is the ultimate and decisive link in the change management. Change without congruence is a non-starter and hence is the most difficult part in change management. The role of change agent is significant in creating congruence.

- Change Agent: The change agent executes Change management. The change agent may be an individual, a team or a firm who is competent to handle the 
change. An ideal change agent is a team from within the organization, consisting of representative/s of the affecting groups, a behavioral expert and a representative of the top management. Change agent has to be fully conversant with the change idea and the change objective and its role is to create change congruence. Change agent from within the organization is more capacitated to win harmony and acceptance in its interactions than a change agent from outside for the simple reason of common belonging of the former. However that will need an unbiased attitude and cohesive approach. A change agent from outside the organization may be more trained in the job and could be more effective in its discrete handling of the change process. It is a matter of judicious decision, depending on the professionalism warranted by the change idea, to have an in-house change agent or an external change agent.

Change management in its implementation by the change agent has to be handled professionally duly balancing the change factors. Change arising from external factors, as already mentioned, is less difficult to implement as its causes are beyond the organizational control. Such change is accepted as a matter of 'fait accompli' and hence may not invoke much resistance from within the organisation. Statutory appointments of specified positions, restriction on operating activities imposed by law, legal embargo on strikes or lockouts, legal sanction for retrenchments etc are a few examples. Change effected by internal factors is likely to invoke resistance and has to be dealt with. Change management thus essentially revolves around resistance management. Resistance, ipso facto, is not a conflict. It is only a symptom which if not properly tackled may lead to a conflict. Change resistance if allowed to grow into a conflict, may delay the change process and it may defer forever. Further, the resistance may not be to the change as such, but to the intrusions or nuances created for achieving the change. Change as explained, is with reference to time factor. If the change is not implemented within a time frame, opportunities could be lost and the very purpose of change could be defeated leading to shifts in change idea. Success of the change agent in managing the change, therefore, heavily depends on its ability to identify and resolve the critical factors of resistance in a change environment.

Let us examine a typical change scenario at the macro level. The latest World Investment Report of the UN Conference on Trade and Development (UNCTAD) observes:

1. FDI (Foreign Direct Investment) into India grew marginally by $1.35 \%$ in 2002 as against decline in worldwide inflows by $21 \%$.

2. China continues to be the biggest rival to India in attracting FDI. 
3. China's FDI inflow is ten times more than that in India and the reasons are:

(i) China opened up its economy in 1979 while India did that in 1991.

(ii) Overseas Chinese contribute much more than NRIs.

(iii) China has 'more business-oriented' and 'FDI-friendly' Policies than India.

(iv) 'FDI procedures are easier' and 'decisions taken rapidly' in China compared to India.

(v) China has more flexible Labor Laws.

In the context of India's need to substantially grow in its FDI, consider 'the Government' as an 'Organization'. All the factors affecting the change - that are listed in points $3(\mathrm{ii})$ to $(\mathrm{v})$ - may be controllable or manageable, but the change factor $(v)$, to have more flexible labor laws may be the most critical of the lot in terms of resistance management. Flexibility in Labor Laws is meant to include more liberal provisions regarding hiring and firing of the employees to suit the investor requirements. For India to initiate this change will need tremendous political dialogue in a multi-party democratic environment. Conviction of change objective in such cases will be limited by the balancing forces of the change factors. The organization may decide to limit the scope of the objective considering its restrictive ability to manage the change resistance. In the instant case the resistance is not to the main change, per se, - expanding FDI - but to the associate change - change of labour laws - to achieve the main change.

Change congruence is the key to the success of change management and is achieved by the change agent. Change congruence is nothing but effective management of change resistance. This needs considerable skills of conviction, anticipation, consistency, analysis, communication, perseverance, tact, persuasion and above all professionalism. Change management is done professionally when it achieves the change goals within the plan period with least resistance. In any change management the change situation has to be examined with reference to its consequence. WHO or WHAT, HOW and WHY of the affected is to be identified. The questions posed are - who is or what is affected by the change? How or to what extent affected? Why is it affected? - If these questions are adequately addressed the resistance gets resolved for smooth installation of the change.

EA Group, a family managed conglomerate having diversified business interests ran into financial difficulty. The Group though had employed professional managers were never a professionally managed enterprise. The Group was guided by the wisdom of the Chairman - the eldest member of the family - a technocrat and a visionary but never a Manager. Even finer details needed the Chairman's approval and the Chairman neither encouraged professional suggestions nor was he in the habit of taking advice. Aggressive expansions not supported by strategic plans, and lacked by sound financial management pushed the group down from a well- 
respected position to a status of potential bankruptcy. Turn-round had to be planned and by default, a professional manager, a confidante of the group, was given the responsibility. The Manager was asked to take up one company at a time. The Manager took up the challenge but put forth 'professional management' as the first pre-condition to commence the task. The change in management style was not to the liking of the Board of Directors (family members), but had no other alternative. The manager was given the freedom and authority to proceed. The management culture, transparency and systems introduced by the manager starled producing results and in about eighteen months time, the lost reputation started recovering.

The case illustrated is typical of strategic change and the manager could convince the affected-Board of Directors, of the need for change in management style. The congruence was not too difficult as the Chairman who could influence the Board was able to objectively accept the need for change. However, had the chairman opted for the change much earlier, possibly the situation that forced the change could have been avoided.

'Who' are affected by the change must be listed down and analyzed as to 'how' and 'why' of the effects. As already mentioned, any change may affect either financial resource or personnel resource or both. Assuming that no change will have an unlawful design, there can be no other relative factor that may be affected by change. The impact of change on financial resources being a matter of treasury function, the only affected factor that may resist change and needing attention shall be the personnel or the human resources. The perspective of the affected must be examined to logically remove their mental blocks towards acceptance of the change. Views of the affected are empathetically considered and all realistic concerns are addressed fully. In the process of assessing the concerns, its germinating cause needs to be looked into in order to effectively resolve those concerns. All concerns are fear-oriented - whether it is fear of losing position, power or money. Open dialogue with the affected with due recognition of the concerns and its resolution eliminate the resistance for Change. Change may be sequenced parallel to resistance removal to gain the confidence of the resisting factors. Sometimes resistance could be imposed by collective opinion rather than by realistic concerns. Politically motivated trade union led resistances are typical examples. Such situations may be dealt with tactfully but firmly without sacrificing the change objective. It may also be done by 'locking of the resistance' with legal assistance. The resistance factor will be segregated and carried forward for possible future resolve, while the change is implemented.

Change management, we may conclude, is a tool for organizational challenge; a function of leadership coordination and a continuous thought process of weeding out differences towards integrated growth of the enterprise. 